\title{
Smaller loads reduce risk of back injuries during wine grape harvest
}

\author{
James M. Meyers \\ John A. Miles \\ Julia Faucett \\ Fadi Fathallah \\ Ira Janowitz \\ Rhonda Smith \\ Ed A. Weber \\ $\nabla$
}

Hand-harvest work in wine grape vineyards is physically demanding and exposes workers to a variety of ergonomics risk factors. Analysis of these exposures together with data on reported work-related injuries points to the risk of back injury as a prevention priority, in particular the lifting and carrying of tubs of cut grapes (weighing up to 80 pounds) during harvest. Our study evaluated the effectiveness of an intervention - the use of a smaller picking tub - on the incidence of musculoskeletal symptoms among workers during two harvest seasons. Reducing the weight of the picking tub by about one-fifth to below 50 pounds resulted in a five-fold reduction in workers' postseason musculoskeletal symptom scores, without significant reductions in productivity.

$\mathrm{B}$ ack injuries are the most common and costly of work-related injuries in agriculture. This is also true of other industries: overall, back injuries are the most frequently cited cause of disability in persons aged 45 or younger, and they account for the most lost time from work as well as a significant proportion of workers' compensation costs (Andersson 1981; Clemmer et al. 1991; Webster and Snook 1990; Glisan 1993; Hashemi et al. 1997).

Total costs for a first-time back injury can reach $\$ 10,000$, with costs for repeated back injuries reaching as much as \$300,000 (OSU Research News 2001; NRC-IOM 2001). With an average of 3,350 back injuries reported each year

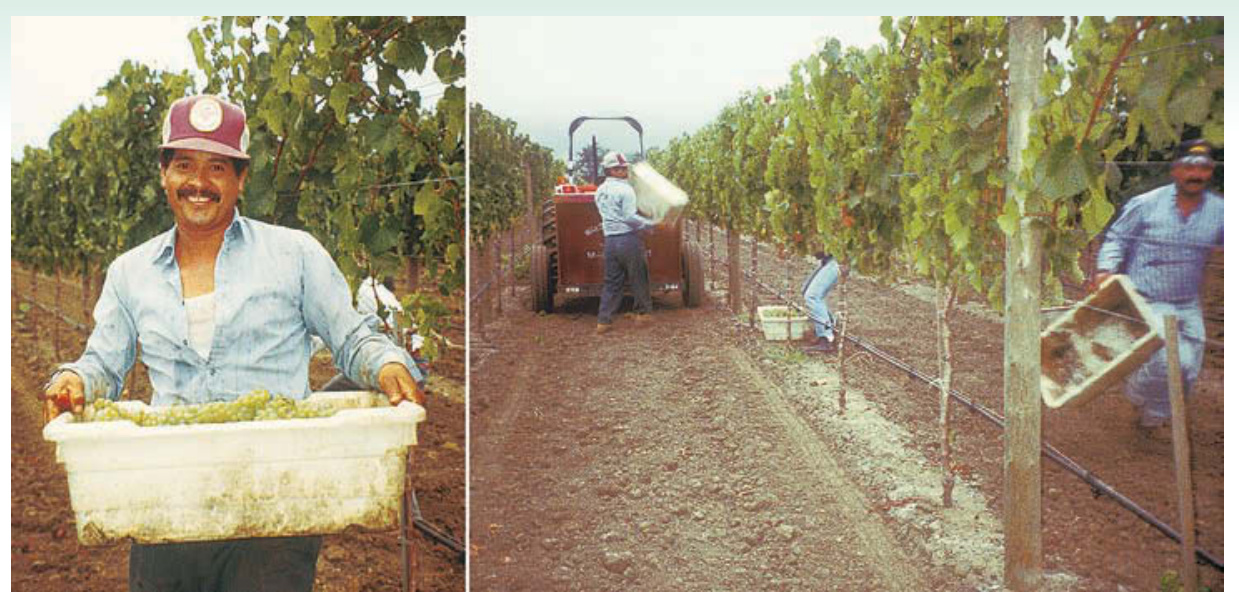

In wine grape vineyards, harvest workers suffer from a high rate of musculoskeletal disorders. Switching to a smaller picking tub can reduce the level of reported symptoms without significantly affecting productivity.

in California agriculture (AgSafe 1992), a conservative annual cost estimate for back injuries is more than $\$ 30$ million.

The causes of occupational back injury are well understood. Literature reviews indicate that heavy physical work, repeated lifting and twisting are consistently associated with greater risk. Generally, those with the heaviest labor duties have the largest numbers of injuries (including to the lower back), and lifting causes more than half of back injuries reported.

Marras et al. (1993, 1995) developed a dynamic methodology for identifying specific factors associated with known job tasks, using a spinal movement feedback monitor (Lumbar Motion Monitor). Marras identified five risk factors involved in manual lifting that predicted increased risk of injury in both medium- and high-risk jobs: lifting frequency, load moment (weight of the object times its distance from the lower back), trunk lateral velocity, trunk twisting velocity and sagittal (or forwardbending) angle.

More problematic is the issue of preventing workplace back injuries. Despite the considerable research in this area, Leamon (1994) points out that there is a paucity of research on the practical application of major theoretical models of causation to risk reduction. Most prevention continues to emphasize worker training. However, interventions aimed at reducing injury through changing worker behavior have generally failed to show any statistically significant effect on the incidence of back injuries. Contrary to general belief and industry practice, training is regarded by safety professionals as the least effective way to reduce injuries. By contrast, interventions featuring engineering controls to eliminate or reduce hazards themselves have been shown to be effective (Echard et al. 1987).

\section{Ergonomics in agriculture}

Since 1994, the UC Agricultural Ergonomics Research Center (UC AERC) has conducted a program of ergonomics research and intervention in agricultural workplaces, with a special focus on preventing back injuries. The focus of these projects has been to identify ergonomics risk factors associated with injury, and then to design and demonstrate low-cost engineering interventions to modify tools or tasks within existing production practices. Early UC AERC projects focused on plant nurseries and wine grape vineyards, in which researchers found evidence of extremely high rates of musculoskeletal disorders (MSDs): 40 per 1,000 workers $(4 \%)$ in nurseries and floriculture, and 80 per 1,000 workers ( $8 \%$ ) in vineyard operations (Meyers et al. 2001) (for a complete definition of MSDs see box, page 26). These are reported injuries only, and are well above the rates tar- 


\section{GLOSSARY}

Ergonomics: The science of work, which can refer to: removing barriers to quality, productivity and human performance by fitting products, tasks and environments to people; fitting the task or tool to the person; planning work so that it fits the body's physiological efficiencies; and optimizing worker wellbeing and productivity.

Health and symptom survey: Focuses on worker reports of types and degrees of musculoskeletal symptoms in different parts of the body. Given in Spanish by trained interviewers, the survey uses visuals to help overcome cross-cultural misunderstandings. Workers circle areas on a body diagram to indicate where they experience pain and other symptoms. The intensity of pain is characterized by use of the FACES scale:

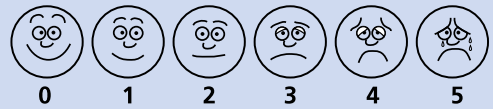

Lumbar Motion Monitor

(LMM): Used to gather functional objective and quantitative measurements of the lumbar range of motion, velocity and acceleration in the work environment. The LMM consists of an exoskeleton that straps to a worker's back and has potentiometers for measurements in three dimensions: (1) range of motion of the worker's back, in terms of sideto-side, twisting and back-and-forth movements; (2) velocity, the worker's speed; and (3) acceleration, the worker's speed divided by time.

Musculoskeletal disorder (MSD): May affect muscles, tendons, joints, nerves and related soft tissues anywhere in the body. Because repeated exposure to force at the same muscle, tendon or region may result in trauma, injury and inflammation, names such as cumulative trauma disorder, repetitive motion injury and repetition strain injury have been applied to these disorders.

Diagnoses most commonly associated with MSDs include: tendonitis or inflammation of a tendon; bursitis or inflammation of the sack surrounding a joint; nerve entrapments such as carpal tunnel syndrome (which pinches the median nerve at the wrist) or cubital tunnel syndrome (which pinches the ulnar nerve at the elbow); myalgia or muscle pain, also referred to as muscle strain, tension neck, or neck and shoulder syndrome. geted by the U.S. Public Health Service (1991), in Healthy People 2000, of an incidence of no more than 60 MSDs per 100,000 workers $(0.06 \%)$.

Injury records for 194 permanent vineyard workers were reviewed for evidence of MSD incidence; these records spanned 2-1/2 years for two employers and 1-1/ 2 years for another. This preliminary study showed the presence of serious risk exposures for a variety of MSDs. Twenty-nine MSDs were defined for 28 (14\%) of the workers studied, representing 435 lost workdays. Back injuries comprised most $(69 \%)$ of the MSDs, with lifting during wine grape harvest cited as a predominate cause (Meyers et al. 2001).

\section{Hand-harvesting wine grapes}

Hand-harvest work is the most physically demanding and intense period during the annual wine-grape crop cycle. Workers move rapidly down a vine row, reaching to grasp grape clusters and cutting them free with a small curved knife. Grapes are dropped into plastic tubs that are moved along with sideways leg thrusts. When the tub is filled the worker lifts and carries it to the gondola (usually on the other side of the picking row), then lifts the tub over his head, leans his body against the vine, and dumps the grapes over the top of that vine into the gondola on the other side. The worker then walks or runs back to his place on the row. Workers make 25 to 50 cuts per minute when picking, and tub weights of up to 80 pounds have been recorded in the field. The job also requires constant forward leaning of the upper torso while locating and cutting grapes. The working heart rate for this job was measured at 119 beats per minute (BPM), which is $70 \%$ higher than a normal resting heart rate of 70 BPM for a healthy young adult. This heart rate is in the range of that for aerobic exercise and is maintained for 6- to 12-hour shifts (except for breaks).

All of these ergonomics risk factors offer opportunities to improve physical efficiencies and reduce strains on the body. However, the repeated heavy lifting and carrying of the filled tubs has been noted as a significant factor in back-injury risk by ergonomists, workers and supervisors, and employer injury records. Focusing on lifting and carrying the tubs also offered an opportunity to test the theoretical suggestion that loads should be reduced to less than 55 pounds, over which destructive effects on the spine become disproportionately dangerous (Davis and Marras 2000).

\section{Lightening the load}

At first glance, it seems obvious that lightening loads that are lifted or carried would reduce back-injury risk, and research supports this approach. However, the problem is more complicated in that workers handle heavier loads differently than lighter loads. Compared to heavier loads, lighter loads may be moved with more bending, velocity and twisting. Additionally, load management is only one part of this complex job task. In changing the way they manage the load, workers become more exposed to other risk factors (for example, more time cutting in a stooped posture) and experience less rest and recovery time.

Finally, recent theoretical and research evidence suggests that there is a spinal loading threshold that may have disproportionate effects on the human spine. Davis and Marras (2000) conducted research on 15 college-age males handling loads of differing weights ranging from 20 to 92 pounds. They found that small increases in load weight ( 6 to 20 pounds) across the range were offset by altered body mechanics (differences in load handling) and yielded little difference in spinal loading (forces acting on the spine). Instead, they found that load weights fell into two distinct groupings: those below and those above 55 pounds. Loads at or exceeding 55 pounds were found to cause significantly more spinal loading and physical stress. In their words, "there appeared to be a weight threshold at 25 kilograms [55 pounds] at which spinal loads became increasingly risky."

Because of this trial's small number of subjects, it is too early to be certain that this proposed threshold applies to the general population. However, the concept of a weight threshold is a new way of thinking about load reduction 
and its effects. Given that farmworkers must routinely lift and carry significant loads, the approach deserved testing in an agricultural setting, especially if lightening a load across this threshold might involve increasing exposure to other risk factors. Because the Davis and Marras (2000) work was preliminary, for our research we decided to use a 50-pound weight target. This provided us with a 5-pound safety margin for fieldwork, to be responsible regarding subject safety; given our results, we stand by the 50-pound target figure for field (as opposed to laboratory) applications.

\section{Smaller picking tub}

Rather than attempting to train workers to load fewer grapes per tub, the engineering intervention we proposed consisted of using smaller plastic tubs for holding and carrying cut grapes during hand-harvest. Several intervention tubs were subjected to an informal field trial with workers in Napa and Sonoma counties during the 1997 harvest to gain worker input to the tub evaluation. A satisfactory, commercially available tub was found, which is 2 inches narrower front to back and 1 inch narrower side to side than the standard tub currently used in California vineyards. Both tubs are 8 inches high, and the external dimensions are 24 inches by 14 inches for the intervention tub and 25 inches by 16 inches for the standard tub (see page 29).

The intervention tubs were $13 \%$ smaller in volume than the standard tubs, resulting in a seasonal average reduction in load weight of 11 pounds (from 57 to 46 pounds) for the tub and its contents. While this is a relatively small weight decrease, it brought average loads below the 50-pound threshold. However, because the intervention tub was smaller, workers would have to make more lifts and carries during each shift to maintain their productivity, as measured in tons of grapes. The intervention tub filled in slightly less time than the standard tub: an average of 2 minutes 46 seconds versus 3 minutes 12 seconds. This means that lifting frequency was slightly greater for the intervention tub than for the standard tub: 21.68 lifts per hour versus 18.75 lifts per

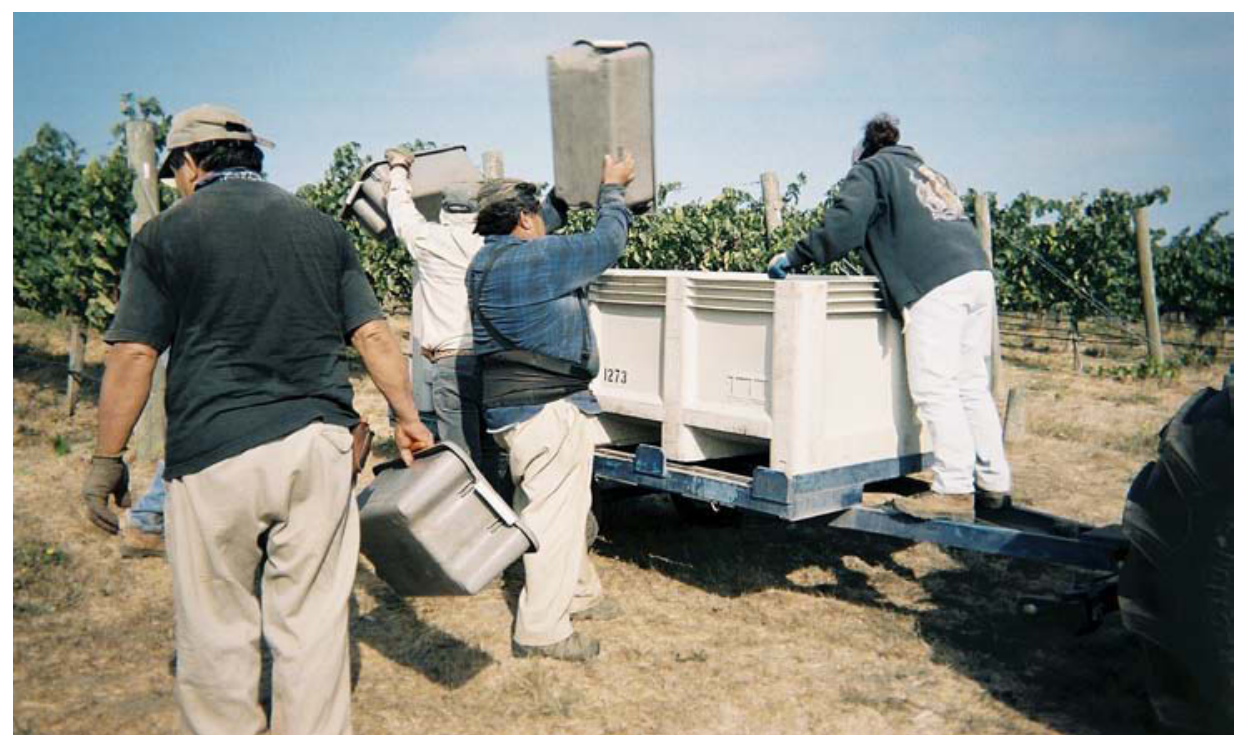

Grape-harvest workers typically dump their full tubs into the gondola 18.75 times per hour; the smaller intervention tub is lighter but must be lifted about 21.68 times per hour. While workers in this study delivered about 168 pounds less grapes per 8-hour shift with the smaller tub, neither they nor their bosses perceived a productivity decline because the reduction was small (only $2.5 \%$ ).

hour. Therefore, lifting repetition would be increased as a trade-off for lowering the weight per lift.

Furthermore, because it is narrower front to back, the intervention tub is carried closer to the body, bringing the load's center of gravity closer to the body. It also has a smooth bottom (as opposed to some standard tubs that are bifurcated with two ribs), making it easier for workers to slide the tub across the ground with their legs while moving along the vine row. This sliding is done three to five times per tub load (depending on the grape variety), and places high shear forces (forces that are applied in the right-to-left or forwardto-backward direction within the body) on the back and knee. The intervention tub requires about two-thirds as much sliding force as the standard tub (13 pounds vs. 19 pounds on level ground).

\section{Intervention trial design}

The intervention evaluation was designed as a pre- and post-trial with each worker serving as his or her own control. More than 200 harvest workers from three wineries and one vineyardmanagement company in Napa and Sonoma counties participated in the intervention trials. Harvest trials consisted of one season using the larger standard tub (1997) and two seasons using the smaller intervention tub exclusively (1998 and 1999).

Preliminary results from the 1998 intervention-tub trial, when compared with the 1997 standard-tub trial, suggested that the decrease in tub size was having a significant positive effect. However, there was concern that the total crop was significantly lighter in 1998 due to the El Niño weather phenomenon, which may have meant that workers were not taxed as hard as they were in 1997, a heavy crop year. To ensure the validity of trial results, we undertook a second trial using the intervention tub during the 1999 season. For the biomechanical and postural analysis, we applied two standardized instruments, the Lumbar Motion Monitor (LMM) (Marras et al. 1993) and the revised NIOSH Lifting Equation (Waters et al. 1994), to the harvest-tub lifting and carrying task.

\section{Lumbar Motion Monitor (LMM).}

It is often difficult to apply research instrumentation in a working environment. For example, the LMM consists of an exoskeleton worn by the subject (see box page 26, photo page 29). Neither workers nor their supervisors wanted work inhibited during the important harvest period, when workers are paid on a piece-rate basis. Therefore, LMM measurements were conducted in a simulation of a working vineyard. Weighted bags were attached to vine cordons to substitute for grape clusters. To simulate grape harvesting, 10 experienced workers wearing the LMM exoskeleton filled picking tubs with the bags, lifted and carried the tubs, and dumped the contents into a container 
placed at the same height as field gondolas. Lift frequency was standardized for all workers. By making the simulation match real field conditions, workers wearing the LMM performed the same movements at the same pace as workers observed during harvest.

The LMM is essentially a triaxial electrogoniometer that quantitatively describes the movement of the subject's trunk in three dimensions as the task is performed. The LMM acts as an exoskeleton of the spine, which continuously tracks position (degrees of motion) and velocity and acceleration (degrees of motion per second). This instrument was primarily used in this study to supplement the description of hand-harvest task ergonomics. Associated with LMM data is a model based on 5 years of research with workers at Ohio State University, which has been shown to predict whether a lifting job is likely to result in a high backinjury rate (OSU Research News 2001). This model reports predicted injury likelihood as percentage probability and is also now accepted in the field as a standardized instrument (Marras et al. 2000).

NIOSH Lifting Equation. The NIOSH Lifting Equation (Waters et al. 1993, 1994) uses quantitative data describing the human performance of a lifting task to calculate a recommended weight limit for that task. The recommended weight limit is defined as the load weight that most healthy workers could sustain for a period of up to 8 hours without increased risk of lower-back pain. The real load weight is then divided by the recommended weight limit to produce a lifting index (LI) for the tub-lifting task that describes the physical stress experienced by workers. We used this equation to calculate LI figures for the task using both the standard and intervention tubs. An LI of 1.0 is considered normal; results below 1.0 are positive while those above are negative in terms of worker health outcome (an LI greater than 1.0 poses an increased risk for lifting-related lowerback pain and injury for some fraction of the workforce). The NIOSH Lifting Equation is also recognized in the field as a standardized instrument.

\section{Health effects analysis}

There are several reasons why it is difficult to assess occupational MSDs related to ergonomics intervention in agricultural settings. First, workrelated MSDs can take months or years to develop, making it unlikely that reportable or diagnosable injuries would be reported during the study period. Moreover, it is unlikely that employer health records provide an accurate picture of MSD incidence among agricultural workers due to a class-based and cultural propensity to disregard physical discomfort. In addition, workers in discomfort often utilize self or home remedies rather than seeking help from organized community health-care systems.

Symptom survey. To enhance our power to test differences in musculoskeletal outcomes, we employed a musculoskeletal symptom survey developed and used in prior NIOSHfunded studies (see box, page 26) (Faucett et al. 2001). The survey was designed to be compatible with the cultural, linguistic and educational characteristics of Mexican field workers in California agriculture. The survey is delivered in English or Spanish by interview; uses previously tested measures of pain severity, location and duration; and includes items to assist with determining the workrelatedness of the symptoms.

The Spanish translation of the survey underwent extensive forward and backward translation with focus groups of California farmworkers to ensure the appropriateness of the vocabulary and syntax. As with any self-reported survey method, there is potential for subjective bias on the part of the respondent and the interviewer. Still, this approach has demonstrated sensitivity in its potential for capturing changes in MSD symptom development and characterization.

Workers were given symptom surveys at the beginning and end of each harvest period (approximately 8 to 10 weeks in length), and the change in symptoms was computed for each harvest. From fall 1997 to fall 1999, 263 workers participated in this part of the study. In fall 1997, 195 workers completed both the pre- and postharvest surveys. In 1998, we were able to complete pre- and postharvest interviews with 116 workers who had participated in fall 1997. In fall 1999, we were able to reinterview 66 workers who had participated in both the 1997 and 1998 harvest-season interviews. Complete data was available for 115 workers at the end of 1998 and 64 workers at the end of 1999 (including pre- and postharvest data for each preceding year). Workers who completed all interviews did not differ statistically from those who only completed the initial survey interviews in 1997, in terms of their demographics (age, years in the United States, years worked in vineyards and years worked in California vineyards).

Productivity analysis. Productivity impact was assessed by monitoring the tons of grapes picked by participating crews on a daily basis. Tons picked and delivered to the winery is a figure regularly measured by all cooperators.

\section{Intervention vs. standard tubs}

Ergonomics. Our ergonomics assessment of intervention-tub use showed large reductions in targeted risk-factor exposures. Weight was reduced 19\%,

\begin{tabular}{|c|c|c|c|c|}
\hline \multirow[b]{3}{*}{ Symptom } & \multicolumn{4}{|c|}{$\begin{array}{l}\text { TABLE 1. Frequency of reported musculoskeletal symptoms } \\
\text { among vineyard workers in Napa and Sonoma counties }(n=116)\end{array}$} \\
\hline & \multicolumn{2}{|c|}{1997} & \multicolumn{2}{|c|}{1998} \\
\hline & Preharvest & Postharvest & Preharvest & Postharvest \\
\hline & $\cdots$ & $\ldots \ldots \ldots$ & $\cdots$ & $\ldots \ldots$ \\
\hline Musculoskeletal & $18(21)$ & $70(81)$ & $22(26)$ & $33(38)$ \\
\hline Aching & $13(15)$ & $68(79)$ & $19(22)$ & $32(37)$ \\
\hline \multicolumn{5}{|l|}{ Body location } \\
\hline Hand & $1(1)$ & $0(0)$ & $2(2)$ & $2(2)$ \\
\hline Forearm & $1(1)$ & $3(3)$ & $2(2)$ & $3(3)$ \\
\hline Elbow/upper arm & $2(2)$ & $4(5)$ & $1(1)$ & $4(5)$ \\
\hline Neck/shoulders & $6(7)$ & $16(18)$ & $5(6)$ & $11(13)$ \\
\hline Back & $7(8)$ & $46(53)$ & $13(15)$ & $23(27)$ \\
\hline Knee & $2(2)$ & $21(24)$ & $5(6)$ & $10(12)$ \\
\hline Feet & $2(2)$ & $5(6)$ & $1(1)$ & $4(5)$ \\
\hline
\end{tabular}




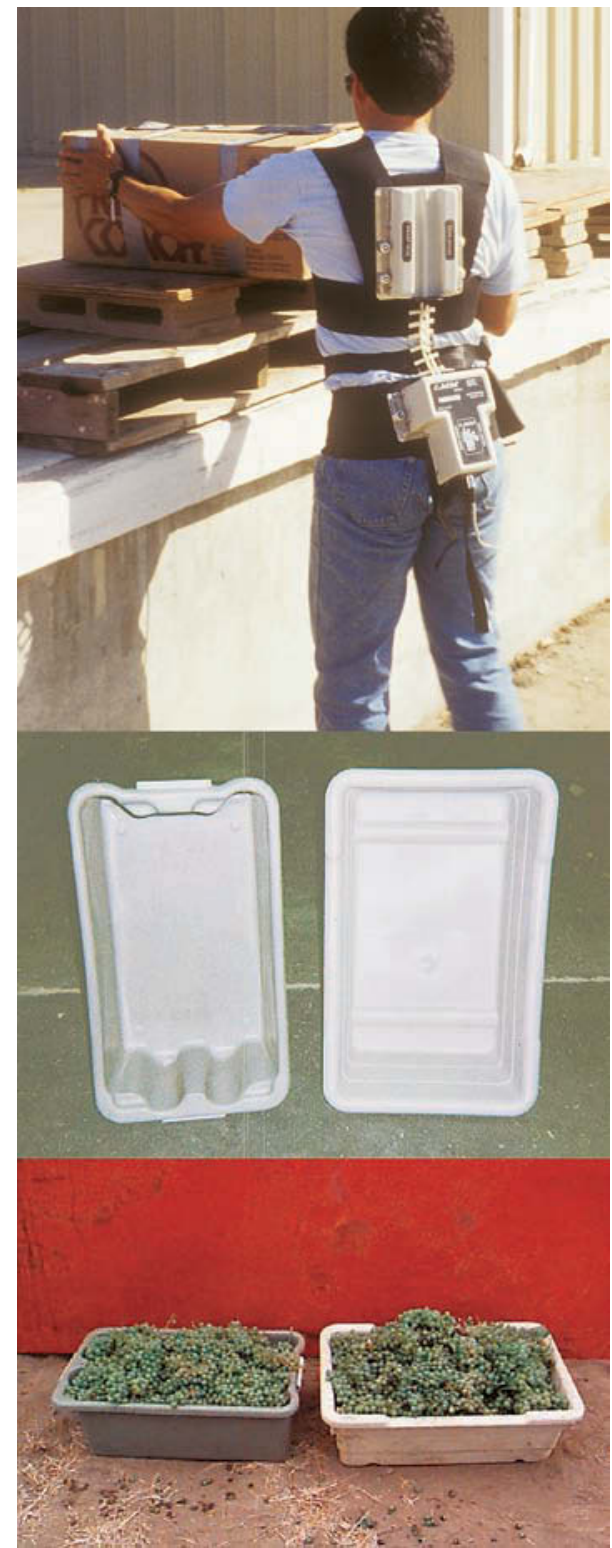

Top, the authors fitted workers with an exoskeleton called a Lumbar Motion Monitor to study their movements during a simulated hand-harvest of grapes. Middle, the intervention tub (left) and standard tub (right). Note the smooth bottom and added handles on the intervention tub. Bottom, the intervention tub holds an average of 11 pounds less grapes than the standard tub.
These results point to a significant opportunity to reduce the risk of back injury in all jobs that require repeated lifting of heavy loads by reducing load weights to $\mathbf{5 0}$ pounds or less. from 57 pounds on average for the standard tub to 46 pounds for the intervention tub. Sliding force was reduced $32 \%$, from 19 to 22 pounds for the standard tub, and 13 to 16 pounds for the intervention tub. Application of the NIOSH Lifting Equation yielded an LI reduction of one full point (from 3.4 to 2.4), indicating decreased risk of injury. This was echoed by the $4 \%$ to 5\% decrease for the LMM-associated calculation for back-injury probability (from 0.64 to 0.60 ).

MSD symptoms. As expected, there was no significant reduction in the incidence of reported or diagnosed MSDs during the study period. In contrast, symptom reporting was relatively frequent, with aching by far the most common MSD symptom reported by workers (tables 1 and 2).

Of 95 workers who began the 1997 standard-tub harvest with no MSD symptoms, $66(70 \%)$ reported symptoms postharvest. In contrast, of 90 workers who began the 1998 intervention-tub harvest with no symptoms, only 26 $(29 \%)$ reported symptoms postharvest. Detailed statistical analysis comparing the 1997 standard-tub trial and the 1998 intervention-tub trial showed that the latter resulted in significant improvements in symptom scores $(\mathrm{t}=6.310$, $P<0.001)$. The frequency of symptom reporting for the back and knee areas, body regions affected by a significant application of force related to lifting tubs full of grapes, showed reductions in the
1998 postharvest period of 50\% (table 1).

Because the harvest was lighter in 1998 than in 1997, MSD symptom data for the intervention tub was collected in 1999, when the harvest volume was more normal. A comparison of symptom scores between the 1997 standardtub-trial baseline year (70\% increase) and 1999 intervention-tub trial $(46 \%$ increase) again demonstrated significant improvements with use of the intervention tub $(\mathrm{t}=3.127, P<0.002)$. These findings demonstrate that many workers experience work-related MSD symptoms during the wine-grape harvest period and that these symptoms grow worse over the course of the harvest. Both the onset and exacerbation of these work-related symptoms were reduced with the introduction of the intervention tub.

Productivity. Use of the smaller intervention tub resulted in slightly decreased productivity, as measured in pounds delivered to the gondola per shift. There was a mean reduction in grapes delivered to the gondola of 168 pounds per 8-hour work shift (average shift total of about 7,000 pounds per worker before intervention). During the field trials, neither workers nor owner/ operators perceived any productivity difference. This is likely because the decrease was small (2.5\%). Also, field time is not the highest concern to workers or management since payment is for tons delivered, not hours worked.

Because the intervention tub can hold an average of 11 pounds less grapes, it fills faster than the standard tub and workers make about three more trips to the gondola per hour to achieve the same productivity. However, even though workers made more trips per shift, their energy expenditure (as estimated from heart-rate changes; Garg et al. 1978) and MSD symptoms decreased over those recorded for standard-tub use.

\section{High risks to workers}

Because MSDs are chronic, it would be overly optimistic to expect large reductions in their reported incidence over the 8- to 10-week harvest period. For that 
reason, we relied on our original approach to assessing MSD symptoms - an individual survey administered in Spanish by trained interviewers.

The MSD symptom measure is particularly relevant for this group of Hispanic workers, who do not generally recognize early discomfort as symptoms of a disorder and potential impairment, and are reluctant to report injuries. Many of the workers who did not report symptoms in the interview had undertaken self-treatment. We believe that these workers do not identify their sensations as symptoms of health disorders or report them as such for cultural, educational and occupational reasons. These workers have a strong work ethic and are fearful of losing workdays or even their jobs. Additionally, focus group participants reported that unless painful symptoms are genuinely work disabling, it is unlikely that they will be reported as painful (dolor in Spanish); more frequently such sensations are reported as bothersome (molestias) and are regarded as commonplace occurrences to be endured rather than treatable disorders. The survey and our data collection process took these cultural variations into account.

While our sample of vineyards was not randomly selected and may not be fully generalizable to the industry, a suggested MSD incidence rate of 80 per 1,000 workers per year indicates a priority need. This is well above the rates targeted by the U.S. Public Health Service (1991) for an incidence of no more than 60 MSDs per 100,000 workers, and it confirms years of anecdotal evidence that field agricultural jobs are physically demanding and take a physical toll.

Our findings confirm our belief that a large proportion of reported sprain/ strain (injury type) and overexertion injuries (injury cause) are indicative of high MSD incidence (AgSafe 1992). Furthermore, they help explain why so few workers perform these jobs beyond age 35 and raise our concern that we will find similarly high levels of MSD symptoms in other agricultural field jobs. Finally, these results point to a significant opportunity to reduce the risk of back injury in all jobs that require repeated lifting of heavy loads by reducing load weights to 50 pounds or less.

\section{A safer wine-grape harvest}

Manual wine-grape harvesting is highly strenuous and physically demanding work, involving exposure to serious risk factors for chronic back injury. Wine-grape harvest work involves all three of the priority ergonomics risk factors we have observed in other agricultural work: full-body stooped posture, highly repetitive hand-work, and manual lifting and carrying of heavy loads. Our findings show the physical impact of this work as a large increase in MSD symptoms during the 1997 standard-tub trial, with $70 \%$ of workers reporting symptoms.

Using ergonomic methods for riskfactor assessment and tool design, we reduced average tub weights by $19 \%$ to below the prescribed 50-pound threshold. This resulted in a two- to five-fold reduction in workers' postharvest symptom scores. Most importantly, at the end of the 1998 intervention-tub trial, both areas of significant force application related to tub lifting, back and knee, showed reductions of $50 \%$ in reported symptoms. These are largemagnitude health outcomes by any measure, and were achieved with no increase in symptoms for other body regions. Participating workers remarked upon this during the course of harvest. Nonetheless, while tub substitution resulted in an improved NIOSH Lifting Equation outcome from an LI of 3.4 to 2.4 , it still left workers with an elevated risk of back injury (that is, exceeding the target LI of 1.0).

Equally important, the workers, whose endorsement of change is critical to the long-term success of an intervention, accepted the use of the smaller intervention tub. Despite a $2.5 \%$ decrease in worker productivity (measured by pounds of grapes per shift), neither workers nor managers remarked upon this. And because workers are paid on an incentive rate per ton rather than time, this decrease was of minor interest to managers. Because workers prefer the smaller tub for its easier manageability, they reported that the productivity decrease was not of critical interest either. All of the companies cooperating in our project have permanently adopted the smaller picking tubs, which are commercially available, as have other vineyards throughout Napa and Sonoma counties. Taken all together, these results present a strong argument for reducing loads lifted or carried by hand (especially where repetition is a factor) to 50 pounds or less.

J.M. Meyers is Specialist, School of Public Health, UC Berkeley; J.A. Miles is Professor, Department of Biological and Agricultural Engineering, UC Davis; J. Faucett is Professor, Department of Community Health Systems, UC San Francisco; F. Fathallah is Professor, Department of Biological and Agricultural Engineering, UC Davis; I. Janowitz is Senior Ergonomist, Ergonomics Program, UC San Francisco and UC Berkeley; R. Smith is Farm Advisor, UC Cooperative Extension (UCCE), Sonoma County; and E.A. Weber is Viticulture Farm Advisor, UCCE Napa County. The National Institute for Occupational Safety and Health funded this research (Cooperative Agreement PHSCCU912911-01). We appreciate the cooperation of the California vineyard owners, managers and workers who made their workplaces and practices available. The following people contributed directly to the successful completion of this project: Linda Garcia, Nutrition, Family and Consumer Sciences Advisor, UCCE Sonoma County; Diana G. Tejeda, Project Coordinator, UC Davis; Victor Duraj, Project Engineer, UC Davis; and Michael Tarter, Professor of Biostatistics, UC Berkeley.

\section{References}

AgSafe. 1992. Occupational injuries in California agriculture 1981-1990. DANR Pub, Oakland, CA.

Andersson GBJ. 1981. Epidemiologic aspects on low-back pain in industry. Spine 6(1):53-60.

Clemmer D, Mohr D, et al. 1991. Low-back injuries in a heavy industry. II. Labor market forces. Spine 16(7):831.

Davis KG, Marras WS. 2000. Assessment of the relationship between box weight and trunk kinematics: Does a reduction in box weight necessarily correspond to a decrease in spinal loading? Human Factors 42(2): 195-208.

Echard M, Smolenski S, Zamiska M. 1987. Ergonomic considerations: Engineering controls at Volkswagen of America. In: Ergonomic Interventions to Prevent Musculoskeletal Injuries in Industry. American Conference 
of Industrial Hygienists. Lewis Pub.

Faucett J, Meyers J, Tejeda D, et al. 2001. An instrument to measure musculoskeletal symptoms among immigrant Hispanic farmworkers: Validation in the nursery industry. J Agric Saf Health 7(3):185-98.

Garg A, Chaffin D, Herrin G. 1978. Prediction of metabolic rates for manual materials handling jobs. Am Ind Hyg Assoc J 39(8):661-74.

Glisan B. 1993. Customized prevention programs play vital role in back protection process. Occup Health Safety 62(12):21-6.

Hashemi L, Webster BS, Clancy EA, Volinn E. 1997. Length of disability and cost of workers' compensation low back pain claims. J Occupational Environ Med 39(10):937-45.

Leamon TB. 1994. Research to reality: A critical review of the validity of various criteria for the prevention of occupationally induced low back pain disability. Ergonomics 37(12):1959-74.

Marras WS, Allread WG, Burr DL, Fathallah FA. 2000. A prospective validation of a low-back disorder risk model and an assessment of ergonomic interventions associated with manual materials handling tasks. Ergonomics 43(11):1866-86.

Marras WS, Lavender SA, Leurgans SE, et al. 1993. The role of dynamic threedimensional trunk motion in occupationally related low back disorders: The effect of workplace factors, trunk position, and trunk motion characteristics on risk of injury. Spine 18(5):617-28.

Marras WS, Lavender SA, Leurgans SE, et al. 1995. Trunk motion and occupationally related low back disorder risk. Ergonomics 38:377-410.

Meyers J, Miles J, Faucett J, et al. 2001. Priority risk factors for back injury in agricultural field work: Vineyard ergonomics. J Agromed 8(1):37-52.

[NRC-IOM] National Research Council and Institute of Medicine. 2001. Musculoskeletal disorders and the workplace: Low back and upper extremities. Panel on Musculoskeletal Disorders and the Workplace, Commission on Behavioral and Social Sciences and Education. Washington, DC: Nat Acad Pr.

[OSU] Ohio State University Research News. 2001. Landmark study uncovers reasons behind recurring back injury. December. Columbus, OH. http://researchnews. osu.edu/archive/backemg.htm.

US Public Health Service. 1991. Healthy People 2000: National health promotion and disease prevention objectives. US Department of Health and Human Services, Washington, DC. Obj. 10.2.

Waters TR, Putz-Anderson V, Garg A Fine LJ. 1993. Revised NIOSH equation for the design and evaluation of manual lifting tasks. Ergonomics 36(7):749-76.

Waters T, Putz-Anderson V, Garg A. 1994. Applications Manual for the Revised NIOSH Lifting Equation. DHHS (NIOSH) Pub No 94-110.

Webster B, Snook S. 1990. The cost of compensable low back pain. J Occup Med 32(1):13.

\section{New controls investigated for vine mealybug}

\author{
Kent M. Daane \\ Walter J. Bentley \\ Vaughn M. Walton \\ Raksha Malakar-Kuenen \\ Jocelyn G. Millar \\ Chuck A. Ingels \\ Ed A. Weber \\ Carmen Gispert
}

The vine mealybug is a newly invasive pest that has spread throughout California's extensive grape-growing regions. Researchers are investigating new control tools to be used in combination with or as an alternative to standard organophosphate insecticide controls. Insect growth regulators and nicotine-based insecticides provide good alternative pesticides for use in some vineyards. Ongoing studies on the augmentative release of natural enemies and mating disruption also show promise, but commercial products are not yet available to growers.
Tn the early 1990s, the vine mealybug I was accidentally introduced into the Coachella Valley (Gill 1994; Godfrey et al. 2003), probably from Mexican or Argentinian table-grape vineyards. This invasive pest quickly spread to grapegrowing regions in the San Joaquin Valley (1998), Central Coast (1999), North Coast (2001), Sacramento Valley (2002), Sierra foothills (2002) and Monterey area (2002). As of fall 2005, the vine mealybug had been found in 17 California counties, and it is likely that more infestations have not been detected.

Vineyard mealybugs decrease crop quality by excreting honeydew, which promotes sooty molds, and by infesting grape bunches (Flaherty et al. 1992). The vine mealybug (Planococcus ficus [Signoret]) has biological characteristics that make it more damaging than other vineyard mealybugs (Godfrey et al. 2002). For example, the vine mealybug has a high reproductive rate, with some females depositing more than 250 eggs, and a fast development time, with four to seven generations per year in the San

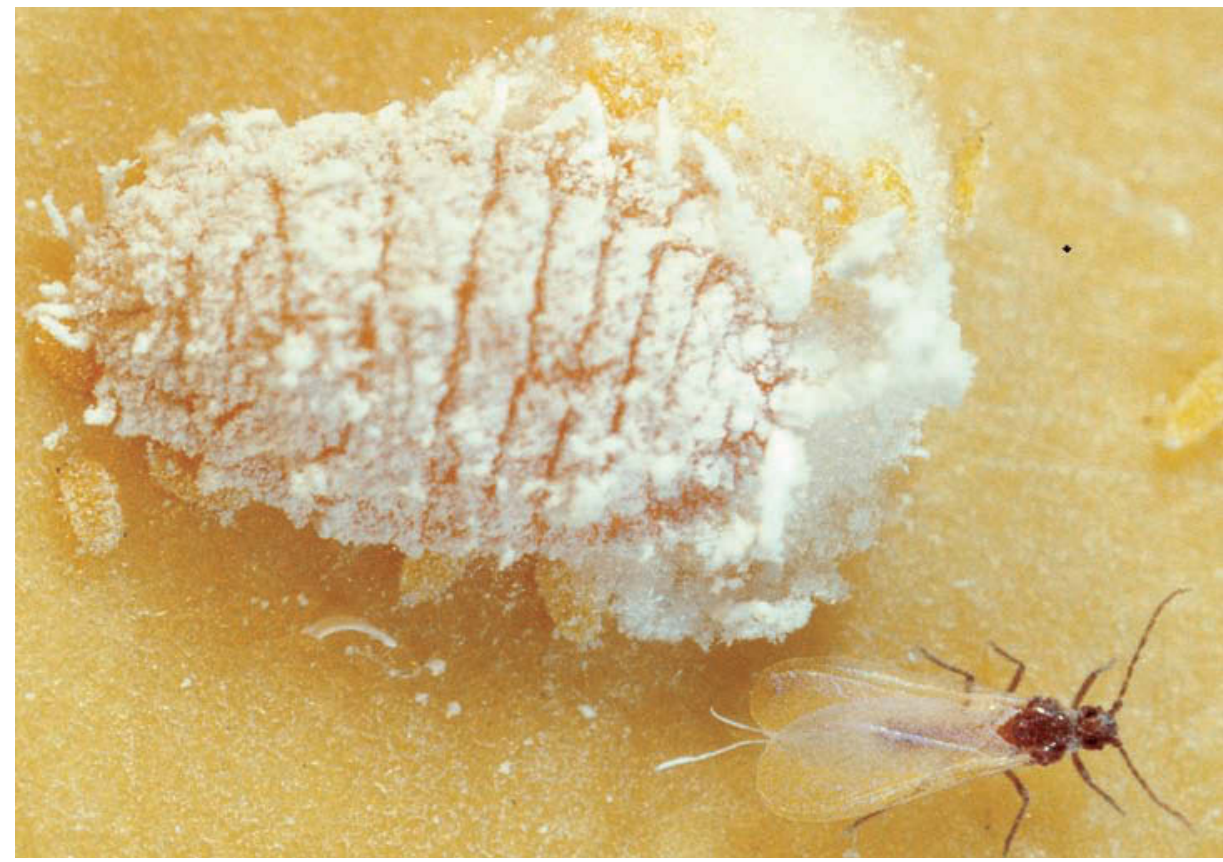

The nonnative vine mealybug, female (left) and winged male (right), excretes abundant honeydew, and infests and feeds on grape leaves and bunches. The authors investigated sustainable alternatives to conventional insecticides, which are often ineffective because the mealybug can reside under the bark. 